\title{
Interaction between ELMO1 gene polymorphisms and environment factors on susceptibility to diabetic nephropathy in Chinese Han population
}

\author{
Yi Hou $^{1 \dagger}$, Yong Gao ${ }^{2 \dagger}$, Yan Zhang ${ }^{3 *}$, Si-Tong Lin ${ }^{3}$, Yue Yu ${ }^{3}$ and Liu Yang ${ }^{3}$
}

\begin{abstract}
Background: The association of diabetic nephropathy (DN) risk with single nucleotide polymorphisms (SNPs) within Engulfment and Cell Motility 1 (ELMO1) gene and gene-environment synergistic effect have not been extensively examined in, therefore, the purpose of this study is to explore the association between multiple SNPs in ELMO1 gene, and the relationship between gene-environment synergy effect and the risk of DN.
\end{abstract}

Methods: Genotyping for 4 SNPs was performed with polymerase chain reaction (PCR) and following restriction fragment length polymorphism (RFLP) methods. Hardy-Weinberg balance of the control group was tested by SNPstats (online software: http://bioinfo.iconologia.net/snpstats). The best combination of four SNPs of ELMO1 gene and environmental factors was screened by GMDR model. Logistic regression was used to calculating the OR values between different genotypes of ELMO1 gene and DN.

Results: The rs741301-G allele and the rs10255208-GG genotype were associated with an increased risk of DN risk, adjusted ORs (95\% Cl) were $1.75(1.19-2.28)$ and $1.41(1.06-1.92)$, respectively, both $p$-values were $<0.001$. We also found that the others SNPs-rs 1345365 and rs 7782979 were not significantly associated with susceptibility to DN. GMDR model found a significant gene-alcohol drinking interaction combination ( $p=0.0107$ ), but no significant gene-hypertension interaction combinations. Alcohol drinkers with rs741301-AG/GG genotype also have the highest DN risk, compared to never drinkers with rs741301-AA genotype, OR (95\% Cl) 3.52 (1.93-4.98).

Conclusions: The rs741301-G allele and the rs10255208-GG genotype, gene-environment interaction between rs741301 and alcohol drinking were all associated with increased DN risk.

Keywords: Diabetic nephropathy, Single nucleotide polymorphisms, Engulfment and Cell Motility 1, Interaction, Smoking, Hypertension, Alcohol

\section{Background}

Diabetic nephropathy (DN) is one of the most destructive microvascular complications of all the complications of diabetes, and it is the main cause of end-stage renal disease (ESRD), which accounts for a large proportion of the morbidity and mortality of diabetes [1]. DN is also an

\footnotetext{
*Correspondence: zhangyanyy36@163.com

${ }^{\dagger}$ Yi Hou and Yong Gao are the co-first author for this paper

${ }^{3}$ Department of Endocrinology, China-Japan Union Hospital of Jilin

University, Changchun 130033, Jilin, People's Republic of China

Full list of author information is available at the end of the article
}

important risk factor for the development of cardiovascular disease and chronic kidney disease [2] and one of the main causes of death [3]. The pathogenesis of DN was multifactorial and was also not been well known. Previous studies have reported that some genetic and environmental risk factors may lead to its progress, including hyperglycemia, hypertension and hyperlipidemia, which were common modifiable risk factors. In addition, some unmodifiable risk factors should also draw public attentions, such as genetic factors $[4,5]$. 
Genome-Wide Association Studies (GWAS) and metaanalysis [6, 7] have reported some genes related with susceptibility to DN in different populations. In 2005, a Japanese GWAS study [8] confirmed that Engulfment and Cell Motility 1 (ELMO1) gene is a new candidate gene. In this study, they evaluated more than 80,000 loci and found that one SNP locus in intron 18 of ELMO1 gene was closely related to $\mathrm{DN}$. Then, some studies also reported that this gene was associated with kidney disease attributed to T2DM in different populations [911], including Chinese populations [11]. The detailed mechanism for association between ELMO1 gene polymorphisms and DN susceptibility was not well known. However, a previous study [12] showed that mutations in elmo1 gene can lead to the disorder of extracellular matrix (ECM) metabolism, which leads to the accumulation of ECM, thickening of renal tubules and glomerular basement membrane, thus increasing the risk of DN. However, to date, the association between DN risk and SNPs within ELMO1 gene have not been extensively examined in Chinese populations. Strong evidences [13, 14] have suggested the important role for the combination of environmental exposures and genetic factors for development or progression of the DN. However, till now, no study investigated the ELMO1 gene-environment interaction. Therefore, the present study aimed to evaluate the impact of four SNPs in the ELMO1 gene, and its interaction with environmental risk factors on susceptibility to DN.

\section{Materials and methods Subjects}

There were a total of 1325 participants including 660 T2DM patients with DN and 665 T2DM patients without DN. Those participants with a fasting glucose $\geq 126 \mathrm{mg} /$ dl $(7.0 \mathrm{mmol} / \mathrm{l})$, or a $2 \mathrm{~h}$ postprandial blood glucose $\geq 200 \mathrm{mg} / \mathrm{dl}(11.0 \mathrm{mmol} / \mathrm{l})$, or if hypoglycemic therapy (oral agents or insulin) had been started were considered as T2DM patients [15]. The diagnostic criteria of DN was made according to World Health Organization 1999 [16]. Those T2DM patients were considered as cases with $\mathrm{DN}$, including those with persistent urine albuminuria more than $300 \mathrm{mg} / \mathrm{l}$ in consecutive twice measurements, or without renal failure: serum creatinine more than $1 \mathrm{mg} / \mathrm{dl}$. Those T2DM patients without DN were included in the control group. All subjects in the study received detailed clinical and biochemical examinations. Those T2DM patients with end-stage renal disease (ESRD) were excluded from both case and control group. All the subjects were Han people, and there was no genetic and blood relationship between any two subjects. Before participating in the study, all subjects understood the content of the study and signed the informed consent. All participants will fill in a self-designed questionnaire, including general demographic information, lifestyle risk factors such as smoking and drinking, physical indicators measurement, the history of major diseases and other data. Smokers are those who report smoking at least once a day for a year or more. Drinking is the sum of milliliters of alcohol extracted weekly from wine, beer and spirits. Hypertension patients were those whose SBP was equal or more than $140 \mathrm{mmHg}$ and/or DBP was equal or more than $90 \mathrm{mmHg}$ and/or use of antihypertensive medication.

\section{Genomic DNA extraction and genotyping}

We selected the SNPs according to two methods as following: firstly, we selected SNPs from ELMO1 gene family; secondly, we selected the SNPs within ELMO1 gene, which have been reported in previous studies, but no consistent results were obtained on the relation between SNPs and DN risk. According to the standard instructions, we will take $3 \mathrm{ml}$ blood samples from all participants, which are processed by EDTA and stored in a refrigerator at $-20{ }^{\circ} \mathrm{C}$ for DNA genomic DNA extraction. Genotyping was performed with a polymerase chain reaction (PCR) and following restriction fragment length polymorphism (RFLP). The description, primers and enzyme for the four SNPs were shown in Additional file 1: Table S1, including rs741301, rs1345365, rs10255208 and rs7782979. A $25 \mu \mathrm{l}$ reaction mixture including $1.25 \mu \mathrm{l}$ SNP Genotyping Assays $(20 \times), 12.5 \mu \mathrm{l}$ Genotyping Master Mix $(2 \times), 20$ ng DNA. PCR cycling conditions consisted of an initial denaturation at $96{ }^{\circ} \mathrm{C}$ for $7 \mathrm{~min}$, followed by 35 cycles of $96^{\circ} \mathrm{C}$ for $20 \mathrm{~s}, 57^{\circ} \mathrm{C}$ for $30 \mathrm{~s}$, and $72{ }^{\circ} \mathrm{C}$ for $45 \mathrm{~s}$, ending with a final elongation step at $72{ }^{\circ} \mathrm{C}$ for $5 \mathrm{~min}$. For quality control, genotyping was performed with blinding to the grouping of participants, and both controls and cases were randomly selected $10 \%$, which were genotyped for two times by different staffs, and the reproducibility should be $100 \%$.

\section{Statistical analysis}

In current study, the Hardy-Weinberg equilibrium (HWE) test and comparison of distribution of alleles and genotypes between case and control groups were performed with Chi-squared test. The mean \pm standard deviation (SDS) was used to represent the continuous variables of normal distribution, and Student $t$ test was used to compare the case group and the control group. Logistic regression model was used to calculate the statistical relationship between four SNPs and DN risk. The best interaction combinations associated with DN among the 4 SNPs in ELMO1 gene was determined with generalized multifactor dimensionality reduction (GMDR), a sign or permutation test (providing empirical $p$ values) 
used for predicting accuracy was employed to measure the significance of an identified model. Statistically significance was determined when $p$-values was less than 0.05 .

\section{Results}

A description for DN patients and normal controls regarding demographic and general or clinical characteristics is shown in Table 1. A total of 1325 participants including 660 T2DM patients with DN and 665 T2DM patients without DN (controls). The average age for all participants was $66.0 \pm 12.8$ years. There was no significant difference found in several parameters, including gender, smoking rates, age, duration of diabetes, FPG and BMI between the two groups (all $p$-values were more than 0.05). In contrast, the percentages of participants who consumed alcohol, hypertension patients, means of HbA1c, creatinine, urea and urine albumin/creatinine ratios (ACR) were higher in the $\mathrm{DN}$ patients than that in controls.

The genotype frequencies in the control of the current study were all distributed accordingly to HWE (Table 2). The frequency of the rs741301-G allele was $30.7 \%$ in DN patients and $20.2 \%$ in normal controls, in addition, the frequency of the rs $10255208-\mathrm{G}$ allele was $28.3 \%$ in DN patients and $20.4 \%$ in normal controls, which was also indicating a significantly statistical difference. The rs741301-G allele and the rs10255208-GG genotype were

Table 1 General characteristics of 1325 study participants in case and control group

\begin{tabular}{lllr}
\hline Variables & $\begin{array}{l}\text { DN patients } \\
(\mathbf{n}=66 \mathbf{)}\end{array}$ & $\begin{array}{l}\text { Normal controls } \\
(\mathbf{n}=665)\end{array}$ & $\boldsymbol{p}$-values \\
\hline Age (year), mean \pm SD & $65.8 \pm 13.8$ & $66.3 \pm 14.3$ & 0.517 \\
Gender, N (\%) & & & 0.652 \\
Males, N (\%) & $378(57.3)$ & $389(58.5)$ & \\
Females, N (\%) & $282(42.7)$ & $276(41.5)$ & \\
Hypertension, N (\%) & $238(36.1)$ & $195(29.3)$ & 0.009 \\
BMl (kg/m²), mean \pm SD & $24.3 \pm 8.4$ & $23.7 \pm 8.1$ & 0.186 \\
Smoking, N (\%) & & & 0.062 \\
Never smoking & $435(65.9)$ & $470(70.7)$ & \\
Ever or current smoking & $225(34.1)$ & $195(29.3)$ & \\
Alcohol drinking, N (\%) & & & 0.0033 \\
Never drinking & $408(61.8)$ & $462(69.5)$ & \\
Ever or current drinking & $252(38.2)$ & $203(30.5)$ & \\
FPG (mmol/l) & $9.3 \pm 3.9$ & $9.1 \pm 3.7$ & 0.338 \\
HbA1c (\%) & $8.57 \pm 3.23$ & $8.28 \pm 3.25$ & 0.029 \\
Duration of diabetes & $10.1 \pm 4.4$ & $9.8 \pm 4.7$ & 0.231 \\
Creatinine (mg/dl) & $1.24 \pm 0.37$ & $1.12 \pm 0.29$ & $<0.001$ \\
Urea (mg/dl) & $40.5 \pm 15.1$ & $35.3 \pm 14.3$ & $<0.001$ \\
ACR ( $\mu$ g/mg) & $82.34 \pm 33.8$ & $22.8 \pm 7.6$ & $<0.001$ \\
\hline
\end{tabular}

$B M /$ body mass index, T2DM type 2 diabetes mellitus, FPG fasting plasma glucose, $A C R$ urine albumin/creatinine ratio associated with an increased risk of DN risk, adjusted ORs $(95 \% \mathrm{CI})$ were $1.75(1.19-2.28)$ and 1.41 (1.061.92), respectively. We also found that the others SNPsrs1345365 and rs7782979 were not correlated with DN susceptibility significantly.

The gene-hypertension or alcohol drinking interaction test were determined by GMDR model (Table 3). We found a significant gene-alcohol drinking interaction combination, but no significant gene-hypertension interaction combinations, after adjusting for age, gender, BMI, smoking and alcohol drinking covariates. A two-locus including rs741301 and alcohol drinking was significantly in the GMDR model. In order to obtain the odds ratios and $95 \% \mathrm{CI}$ for the joint effects of gene-alcohol drinking on DN, we conducted stratified analysis for interaction effect using logistic regression. We found that alcohol drinkers with rs741301-AG/GG genotype also have the highest DN risk, compared to never drinkers with rs741301-AA genotype, OR (95\% CI) 3.52 (1.934.98) (Fig. 1).

\section{Discussion}

In the current study, we found that rs741301-G allele and the rs10255208-GG genotype were associated with an increased risk of $\mathrm{DN}$ risk respectively. We also found that the others SNPs-rs1345365 and rs7782979 were not significantly associated with susceptibility to DN. DN is the most common cause of ESRD and the most common microvascular complication of diabetes mellitus [17]. However, its detailed pathogenesis was not well known yet, and both environmental and genetic factors were reported involving in the occurrence and development of DN susceptibility [18, 19]. ELMO1 is a protein composed of 720 amino acids, encoded by elmo1 gene and located on chromosome $7 \mathrm{p} 14.2-14.1$. It may be a new and powerful candidate gene of $\mathrm{DN}$, which has influence on the movement and phagocytosis of apoptotic cells [20]. Animal studies in mice [21] suggest that ELMO1 protein plays an important role in the pathogenesis of DN and proteinuria. Over the last decade, some studies were performed to test the relationship between ELMO1 gene SNPs and DN risk, but these studies concluded inconsistent results, and few studies were performed in Chinese populations. Mehrabzadeh et al. [22] investigated the relationship between ELMO1-rs741301 and the risk of $\mathrm{DN}$ in Iranian population, and considered that ELMO1-rs741301 is an important candidate gene for DN susceptibility. Bodhini et al. [23] reported a significant association of the ELMO1 rs741301 SNPs with DN in south Indians. Wu et al. [11] also verified the association of rs741301 with DN, and rs1345365 was not associated with DN risk, however the sample size for this study was very small, just 200 unrelated Chinese subjects were 
Table 2 Association analysis for four SNPs within ELMO1 gene and DN susceptibility

\begin{tabular}{|c|c|c|c|c|c|c|}
\hline \multirow[t]{2}{*}{ SNPs } & \multirow[t]{2}{*}{ Genotypes or alleles } & \multicolumn{2}{|l|}{ Frequencies N (\%) } & \multirow[t]{2}{*}{ OR $(95 \% \mathrm{Cl})^{\mathrm{a}}$} & \multirow[t]{2}{*}{$p$-values } & \multirow{2}{*}{$\begin{array}{l}p \text {-values } \\
\text { for HWE test } \\
\text { in controls }\end{array}$} \\
\hline & & $\begin{array}{l}\text { Normal controls } \\
(n=665)\end{array}$ & $\begin{array}{l}\text { DN patients } \\
(n=660)\end{array}$ & & & \\
\hline \multirow[t]{5}{*}{ rs741301 } & AA genotype & $430(64.7)$ & $325(49.2)$ & 1.00 (ref) & & 0.148 \\
\hline & AG genotype & $202(30.4)$ & $265(40.2)$ & $1.68(1.15-2.23)$ & $<0.001$ & \\
\hline & GG genotype & $33(5.0)$ & 70 (10.6) & $2.04(1.29-2.82)$ & $<0.001$ & \\
\hline & A allele & $1062(79.8)$ & $915(69.3)$ & 1.00 (ref) & & \\
\hline & G allele & $268(20.2)$ & $405(30.7)$ & $1.75(1.19-2.28)$ & $<0.001$ & \\
\hline \multirow[t]{5}{*}{ rs1345365 } & AA genotype & $415(62.4)$ & $382(57.9)$ & 1.00 (ref) & & 0.228 \\
\hline & AG genotype & $214(32.2)$ & $235(35.6)$ & $1.20(0.80-1.81)$ & 0.462 & \\
\hline & GG genotype & $36(5.4)$ & $43(6.5)$ & $1.51(0.69-2.32)$ & 0.613 & \\
\hline & A allele & $1044(78.5)$ & $999(75.7)$ & 1.00 (ref) & & \\
\hline & G allele & $286(21.5)$ & $321(24.3)$ & $1.24(0.77-1.95)$ & 0.529 & \\
\hline \multirow[t]{5}{*}{ rs10255208 } & AA genotype & $426(64.1)$ & $351(53.2)$ & 1.00 (ref) & & 0.294 \\
\hline & AG genotype & $207(31.1)$ & $245(37.1)$ & $1.28(0.88-1.77)$ & 0.425 & \\
\hline & GG genotype & $32(4.8)$ & $64(9.7)$ & $1.90(1.30-2.59)$ & $<0.001$ & \\
\hline & A allele & 1059 (79.6) & $947(71.7)$ & 1.00 (ref) & & \\
\hline & G allele & $271(20.4)$ & $373(28.3)$ & $1.41(1.06-1.92)$ & 0.021 & \\
\hline \multirow[t]{5}{*}{ rs7782979 } & CC genotype & $409(61.5)$ & $376(57.0)$ & 1.00 (ref) & & 0.592 \\
\hline & CA genotype & $228(34.3)$ & $242(36.7)$ & $1.20(0.84-1.72)$ & 0.487 & \\
\hline & AA genotype & $28(4.2)$ & $42(6.4)$ & $1.29(0.76-1.97)$ & 0.641 & \\
\hline & Callele & $1046(78.6)$ & $994(75.3)$ & 1.00 (ref) & & \\
\hline & A allele & $284(21.4)$ & $326(24.7)$ & $1.23(0.82-1.76)$ & 0.583 & \\
\hline
\end{tabular}

adjusted for age, gender, BMI, hypertension, smoking and alcohol drinking

Table 3 GMDR analysis for the best interaction combination models

\begin{tabular}{|c|c|c|c|c|}
\hline Locus no. & Best combination & Cross-validation consistency & Testing balanced accuracy & p-values* \\
\hline \multicolumn{5}{|c|}{ Gene-hypertension interactions ${ }^{a}$} \\
\hline 2 & 1, hypertension & $8 / 10$ & 0.598 & 0.6241 \\
\hline 3 & 1,3 , hypertension & $6 / 10$ & 0.562 & 0.377 \\
\hline 4 & $1,2,3$, hypertension & $5 / 10$ & 0.545 & 0.857 \\
\hline 5 & $1,2,3,4$, hypertension & $7 / 10$ & 0.521 & 0.377 \\
\hline \multicolumn{5}{|c|}{ Gene-alcohol drinking interactions ${ }^{b}$} \\
\hline 2 & 1, alcohol drinking & $10 / 10$ & 0.621 & 0.0107 \\
\hline 3 & 1, 3, alcohol drinking & $8 / 10$ & 0.599 & 0.1719 \\
\hline 4 & $1,2,4$, alcohol drinking & $7 / 10$ & 0.558 & 0.3770 \\
\hline 5 & $1,2,3,4$, alcohol drinking & $8 / 10$ & 0.476 & 0.5316 \\
\hline
\end{tabular}

SNPs named with 1-4 were rs 741301, rs 1345365, rs 10255208 and rs7782979 respectively

${ }^{a}$ Adjusted for age, gender, BMI, smoking and alcohol drinking

${ }^{\text {b }}$ Adjusted for age, gender, BMI, hypertension and smoking

enrolled. Some studies including GWAS and replication studies were performed in Japanese type 2 diabetic patients [8], replication studies in American Indian study [10] and GoKinD collection study [9], African American cohorts [24]. The key role of ELMO1 as a DN susceptibility gene has been verified. Although many studies have confirmed that elmo1 is a candidate gene for $\mathrm{DN}$, the risk locus and risk allele are not consistent in all populations [25]. Different perspectives also existed in some studies. Yahya et al. [26] suggested that ELMO1-rs74130 was not associated with susceptibility to DN. Hanson et al. [10] indicated that ELMO1-rs1345365, but not rs741301 


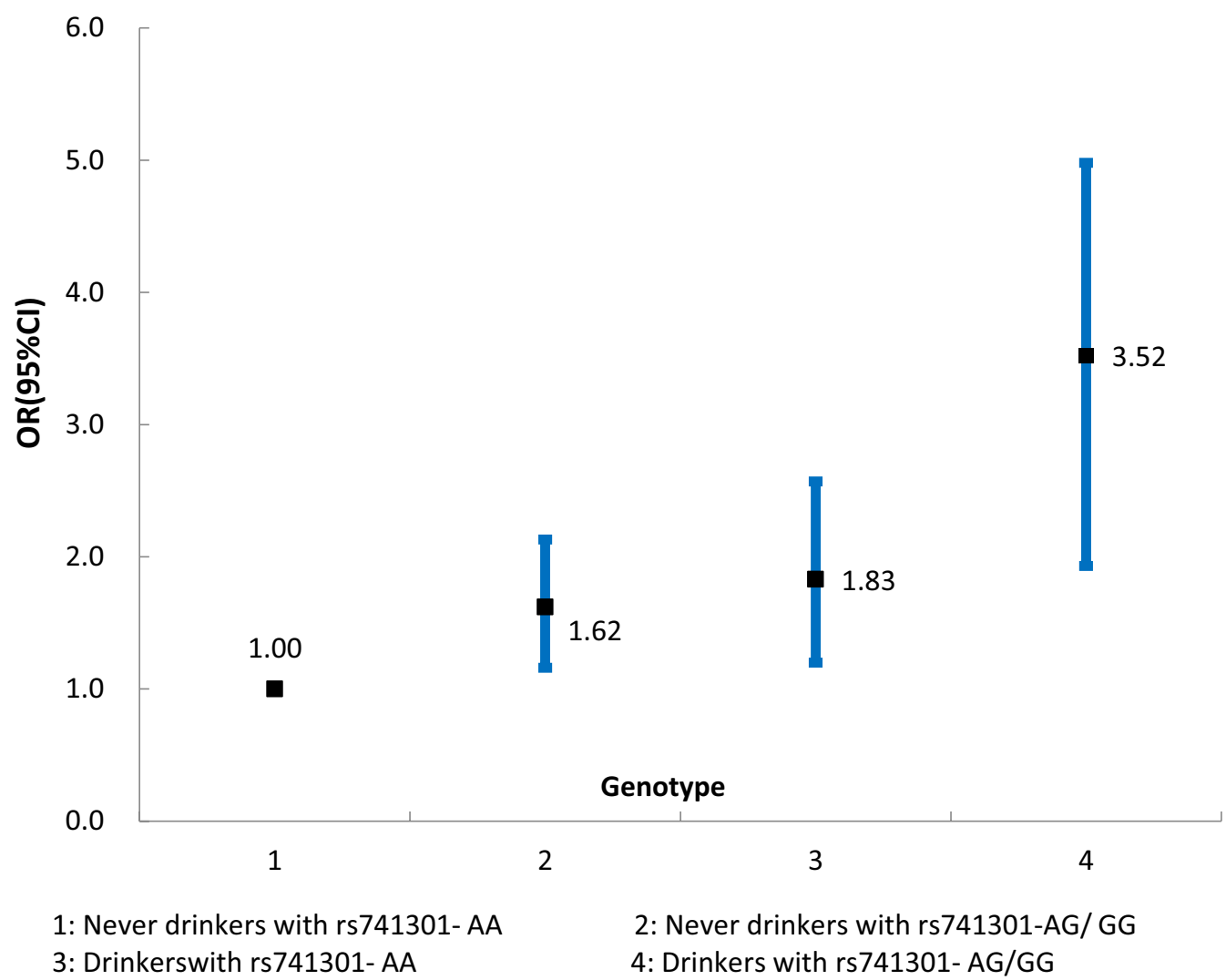

Fig. 1 Stratified analysis for rs 741301 -alcohol drinking interaction on DN risk

associated with DN risk. In terms of rs10255208, which was less studies previously, but this SNP has been reported association with T2DM in Tunisian Arabs [27].

The pathogenesis and process of DN are very complex. The factors of DN susceptibility mainly include genetic factors, environmental factors and the synergistic effect of genetic and environmental factors [28, 29]. Some studies have showed that the interaction between gene and environment factors were associated with the DN risk. This study is the first to confirm the synergistic effect of elmo1 gene polymorphism and environmental factors on DN susceptibility. We found a significant gene-alcohol drinking interaction combination, but no significant gene-hypertension interaction combinations. Alcohol drinkers with rs741301-AG/GG genotype also have the highest DN risk, compared to never drinkers with rs741301-AA genotype. The detailed mechanism for ELMO1 gene-DN association was not well known. However, a previous study [12] showed that mutations in elmo1 gene can lead to the disorder of ECM metabolism, the accumulation of which could thicken of renal tubules and glomerular basement membrane, thus increasing the risk of DN. Another study [21] suggested that ELMO1 also could plays an important role in the development of
DN by increasing oxidative stress (OS), the level of elmo1 gene expression in diabetic mice was consistent with the degree of renal fibrosis and urinary albumin excretion. There was also a positive correlation between ROS and ELMO1 expression.

The limitations of this study were: Firstly, more environment factors should be included in the interaction analysis; secondly, the study population were all Chinese Han, which may not present on behalf of the Chinese populations, because there were 56 races in China. Secondly, just four SNPs were selected for genotyping, more SNPs should be included, and gene-gene interaction should be investigated in the future.

In conclusion, we found that the rs741301-G allele and the rs10255208-GG genotype, gene-environment interaction between rs741301 and alcohol drinking were all associated with increased DN risk. This study not only investigated whether the ELMO1 gene was related to DN susceptibility, but also investigated whether the interaction effect existed between this gene and some significant environmental factors, such as hypertension, alcohol drinking. Previous studies merely investigated this interaction effect between ELMO1 gene and alcohol drinking, especially in Chinese Han populations. 


\section{Supplementary information}

Supplementary information accompanies this paper at https://doi. org/10.1186/s13098-019-0492-0.

Additional file 1: Table S1. Description and primer sequences designed for sequencing 4 SNPs within ELMO1 gene.

\section{Acknowledgements}

We appreciate the cooperation of the families and individuals who cooperated in this study.

\section{Authors' contributions}

$\mathrm{YH}$ : wrote the manuscript, conceived and designed the experiments. YG and STL: experiment operation. YY: data processing and statistical analysis. LY and $Y Z$ : experimental guidance and data verification. All authors read and approved the final manuscript.

\section{Funding}

None.

\section{Availability of data and materials}

Not applicable.

\section{Ethics approval and consent to participate}

We have obtained consent to publish from the participant to report individual patient data.

\section{Consent for publication}

We have obtained consent to publish from the participant.

\section{Competing interests}

The authors declare that they have no competing interests.

\section{Author details}

${ }^{1}$ Department of Urology, China-Japan Union Hospital of Jilin University, Changchun 130033, Jilin, People's Republic of China. ${ }^{2}$ Department of Critica Care, China-Japan Union Hospital of Jilin University, Changchun 130033, Jilin, People's Republic of China. ${ }^{3}$ Department of Endocrinology, China-Japan Union Hospital of Jilin University, Changchun 130033, Jilin, People's Republic of China.

Received: 16 July 2019 Accepted: 9 November 2019

Published online: 27 November 2019

\section{References}

1. Zelmanovitz TGF, Balthazar AS, Thomazelli FCS, Jorge D, Matos JD, Canani LH. Diabetic nephropathy. Diabetol Metab Syndr. 2009;1:1-17.

2. Gnudi L, Coward RJM, Long DA. Diabetic nephropathy: perspec tive on novel molecular mechanisms. Trends Endocrinol Metab. 2016:27(11):820-30.

3. Kos I, Prkacin I. Diabetic nephropathy as a cause of chronic kidney disease. Acta Med Croatica. 2014:68:375-81.

4. Jenum AK, Holme I, Graf-Iversen S, Birkeland Kl. Ethnicity and sex are strong determinants of diabetes in an urban Western society: implications for prevention. Diabetologia. 2005:48:435-9.

5. Temelkova-Kurktschiev T, Stefanov T. Lifestyle and genetics in obesity and type 2 diabetes. Exp Clin Endocrinol Diabetes. 2012;120:1-6.

6. McKnight AJ, Duffy S, Maxwell AP. Genetics of diabetic nephropathy: a long road of discovery. Curr Diab Rep. 2015;15(7):1-11.

7. Mooyaart AL, Valk EJ, van Es LA, Bruijn JA, de Heer E, Freedman BI, Dekkers OM, Baelde HJ. Genetic associations in diabetic nephropathy: a metaanalysis. Diabetologia. 2011;54:544-53.
8. Shimazaki A, Kawamura Y, Kanazawa A, Sekine A, Saito S, Tsunoda T, Koya D, Babazono T, Tanaka Y, Matsuda M, Kawai K, liizumi T, Imanishi M, Shinosaki T, Yanagimoto T, Ikeda M, Omachi S, Kashiwagi A, Kaku K, Iwamoto Y, Kawamori R, Kikkawa R, Nakajima M, Nakamura Y, Maeda S. Genetic variations in the gene encoding ELMO1 are associated with susceptibility to diabetic nephropathy. Diabetes. 2005;54(4):1171-8.

9. Pezzolesi MG, Katavetin P, Kure M, Poznik GD, Skupien J, Mychaleckyj JC, Rich SS, Warram JH, Krolewski AS. Confirmation of genetic associations at ELMO1 in the GoKinD collection supports its role as a susceptibility gene in diabetic nephropathy. Diabetes. 2009;58(11):2698-702.

10. Hanson RL, Millis MP, Young NJ, Kobes S, Nelson RG, Knowler WC, DiStefano JK. ELMO1 variants and susceptibility to diabetic nephropathy in American Indians. Mol Genet Metab. 2010;101(4):383-90.

11. Wu HY, Wang Y, Chen M, Zhang X, Wang D, Pan Y, Li L, Liu D, Dai XM. Association of ELMO1 gene polymorphisms with diabetic nephropathy in Chinese population. J Endocrinol Investig. 2013:36(5):298-302.

12. Shimazaki A, Tanaka Y, Shinosaki T, Ikeda M, Watada H, Hirose T, Kawamori R. Maeda S. ELMO1 increases expression of extracellular matrix proteins and inhibits cell adhesion to ECMs. Kidney Int. 2006;70:1769-76.

13. Pettitt DJ, Saad MF, Bennett PH, Nelson RG, Knowler WC. Familial predisposition to renal disease in two generations of Pima Indians with type 2 (non-insulin-dependent) diabetes mellitus. Diabetologia. 1990;33(7):438-43.

14. Quinn M, Angelico MC, Warram JH, Krolewski AS. Familial factors determine the development of diabetic nephropathy in patients with IDDM. Diabetologia. 1996;39(8):940-5.

15. American Diabetes Association. Diagnosis and classification of diabetes mellitus. Diabetes Care. 2012;35(Suppl. 1):S64-71

16. World Health Organization. Part 1: diagnosis and classification of diabetes mellitus: report of a WHO consultation. In: Alwan A, King H, editors. Definition, diagnosis and classification of diabetes mellitus and its complications. Geneva: Word Health Department of Noncommunicable Disease Surveillance; 1999.

17. Betz B, Conway BR. Recent advances in animal models of diabetic nephropathy. Nephron Exp Nephrol. 2014;126(4):191-5.

18. Sidaway P. Diabetes: epigenetic changes lead to impaired wound healing in patients with T2DM. Nat Rev Endocrinol. 2015;11(2):65.

19. Keating ST, El-Osta A. Epigenetic changes in diabetes. Clin Genet. 2013;84(1):1-10.

20. van Ham TJ, Kokel D, Peterson RT. Apoptotic cells are cleared by directional migration and elmo1-dependent macrophage engulfment. Curr Biol. 2012:22(9):830-6.

21. Hathaway CK, Chang AS, Grant R, Kim HS, Madden VJ, Bagnell CR Jr, Jennette JC, Smithies O, Kakoki M. High Elmo1 expression aggravates and low Elmo1expression prevents diabetic nephropathy. Proc Natl Acad Sci USA. 2016;113(8):2218-22

22. Mehrabzadeh M, Pasalar P, Karimi M, Abdollahi M, Daneshpour M, Asadolahpour E, Razi F. Association between ELMO1 gene polymorphisms and diabetic nephropathy in an Iranian population. J Diabetes Metab Disord. 2016;15:43

23. Bodhini D, Chidambaram M, Liju S, Revathi B, Laasya D, Sathish $N_{\text {, }}$ Kanthimathi S, Ghosh S, Anjana RM, Mohan V, Radha V. Association of rs11643718 SLC12A3 and rs741301 ELMO1 variants with diabetic nephropathy in south Indian population. Ann Hum Genet. 2016;80(6):336-41.

24. Leak T, Perlegas P, Smith S, Keene KL, Hicks P, Langefeld C, et al. Variants in intron 13 of the ELMO1 gene are associated with diabetic nephropathy in African Americans. Ann Hum Genet. 2009:73(2):152-9.

25. Chang Y-C, Chang EY-C, Chuang L-M. Recent progress in the genetics of diabetic microvascular complications. World J Diabetes. 2015:6(5):715.

26. Yahya MJ, Ismail PB, Nordin NB, Akim ABM, Yusuf WSBM, Adam NLB, Yusoff MJ. Association of CCL2, CCR5, ELMO1, and IL8 polymorphism with diabetic nephropathy in Malaysian type 2 diabetic patients. Int J Chronic Dis. 2019:2019:2053015.

27. Turki A, Mzoughi S, Mtitaoui N, Khairallah M, Marmouch H, Hammami S, Mahjoub T, Almawi WY. Gender differences in the association of ELMO1 genetic variants with type 2 diabetes in Tunisian Arabs. J Endocrinol Investig. 2018:41(3):285-91. 
28. Cai W, Li J, Xu JX, Liu Y, Zhang W, Xiao JR, Zhu LY, Liu JY. Association of 2184AG polymorphism in the RAGE gene with diabetic nephropathy in chinese patients with type 2 diabetes. J Diabetes Res. 2015;2015:310237.

29. Zhang Y, Jia N, Hu F, Fan N, Guo X, Du H, Mei C, Gao C. Association of single-nucleotide polymorphisms in the RAGE gene and its gene-environment interactions with diabetic nephropathy in Chinese patients with type 2 diabetes. Oncotarget. 2017;8(57):96885-92.

\section{Publisher's Note}

Springer Nature remains neutral with regard to jurisdictional claims in published maps and institutional affiliations.
Ready to submit your research? Choose BMC and benefit from:

- fast, convenient online submission

- thorough peer review by experienced researchers in your field

- rapid publication on acceptance

- support for research data, including large and complex data types

- gold Open Access which fosters wider collaboration and increased citations

- maximum visibility for your research: over 100M website views per year

At BMC, research is always in progress.

Learn more biomedcentral.com/submissions 